\title{
Rebuilding soil organic $C$ stocks in degraded grassland by grazing exclusion: a linked decline in soil inorganic $\mathbf{C}$
}

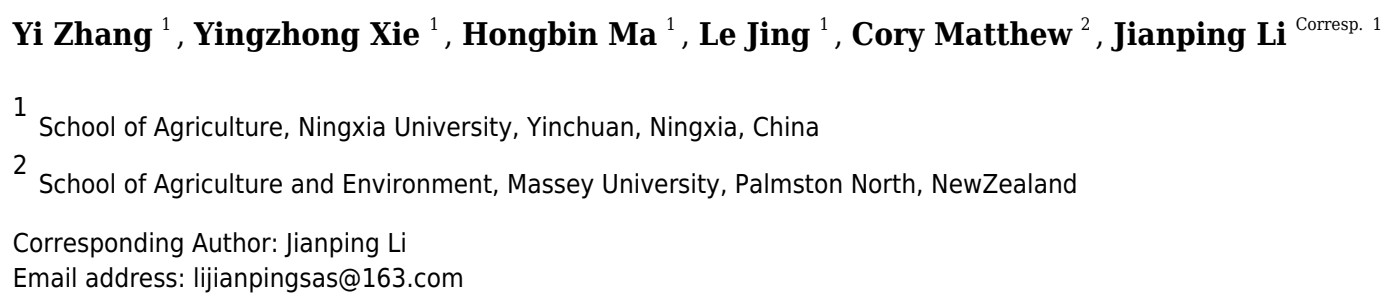

Background: Our study evaluated how soil organic carbon (SOC) and soil inorganic carbon (SIC) recovered over time in deep loessial soil as overgrazed grassland was fenced and restored. Methods: The study was conducted in the Yunwu Mountain Nature Reserve in the Ningxia Autonomous Region of China. In it we compared soil data from three grazed grassland (G) sites, three sites that were fenced for 15 years (F15), and three sites that were fenced for 30 years (F30) as a so-called 'space for time series'. Results and Discussion: We compared SOC accumulation in soil up to $200 \mathrm{~cm}$ below the surface in F15, G, and F30 plots. An increase in SOC correlated with increased soil water holding capacity, a decrease in soil $\mathrm{pH}$, and decreased soil bulk density. However, SOC sequestration in fenced plots was largely offset by a decrease in SIC, which was closely correlated $(r=0.713, p=0.001)$ with SOC-driven soil $\mathrm{pH}$ decline. We observed no significant increase in soil total carbon in the F15 or F30 sites after comparing them to $\mathrm{G}$. Conclusions: This research provides new approaches to the calculation of greenhouse gas inventories used in land use planning. Our data indicate that fencing causes the slow diffusion processes to intensify the soil property changes from increased litter return, and this slow diffusion process is still active 30 years after fencing at $100-200 \mathrm{~cm}$ soil depths in the studied deep loessial soil. These findings are likely applicable to similar sites. 
1

2

3 Yi Zhang ${ }^{1}$, Yingzhong Xie ${ }^{1}$, Hongbin $\mathrm{Ma}^{1}$, Le Jing ${ }^{1}$, Cory Matthew ${ }^{2}$, Jianping $\mathrm{Li}^{1}$,*

4

$5{ }^{1}$ School of Agriculture, Ningxia University, Yinchuan, Ningxia, China

$6{ }^{2}$ School of Agriculture and Environment, Massey University, Palmerston North, New Zealand

$7 \quad *$ Corresponding Author:

$8 \quad$ Jianping $\mathrm{Li}$

9 Yinchuan, Ningxia, China

10

11

12

13

14

15

16

17

18

19

20

21

22

23

24

25

26

27

\section{decline in soil inorganic $\mathrm{C}$}

E-mail address: lijianpingsas@163.com 
29 Abstract

30 Background: Our study evaluated how soil organic carbon (SOC) and soil inorganic carbon

31 (SIC) recovered over time in deep loessial soil as overgrazed grassland was fenced and restored.

32 Methods: The study was conducted in the Yunwu Mountain Nature Reserve in the Ningxia

33 Autonomous Region of China. In it we compared soil data from three grazed grassland (G) sites,

34 three sites that were fenced for 15 years (F15), and three sites that were fenced for 30 years (F30)

35 as a so-called 'space for time series'.

36 Results and Discussion: We compared SOC accumulation in soil up to $200 \mathrm{~cm}$ below the 37 surface in G, F15, and F30 plots. An increase in SOC correlated with a decrease in soil pH, and 38 decreased soil bulk density. However, SOC sequestration in fenced plots was largely offset by a 39 decrease in SIC, which was closely correlated $(r=0.713, p=0.001)$ with SOC-driven soil $\mathrm{pH}$ 40 decline. We observed no significant increase in soil total carbon in the F15 or F30 sites after 41 comparing them to $\mathrm{G}$.

42 Conclusions: Our data indicate that fencing causes the slow diffusion processes to intensify the 43 soil property changes from increased litter return, and this slow diffusion process is still active 30 44 years after fencing at 100-200 cm soil depths in the studied deep loessial soil. These findings are 45 likely applicable to similar sites. 


\section{Introduction}

Grassland is one of the widest distributed vegetation types, and the type of land most affected by human activities (Deng et al., 2016; Wu et al., 2016). A major component of terrestrial ecosystems, grassland accounts for approximately $25 \%$ of global total land area and $10 \%$ of global carbon stocks, playing a vital role in the global carbon cycle (Wang et al., 2016). Soil carbon pools are the largest carbon pools in terrestrial ecosystems with carbon stocks about 3.8 times higher than bio-carbon stocks and three times higher than atmospheric carbon stocks. Soil carbon stock changes help regulate changes in atmospheric $\mathrm{CO}_{2}$ concentration (Fan et al., 2013; Ping \& Wang 2018). Even a small change in the soil organic carbon (SOC) pool can significantly alter the atmosphere's greenhouse gas content (Dou et al., 2013; Srinivasarao et al., 2014). The soil carbon pool includes both SOC and soil inorganic carbon (SIC). SOC is mainly derived from animal and plant residues, and soil microorganisms and their secretions, which are active in and provide fertility to soil. SIC is the main form of soil carbon found in arid regions and includes compounds such as soil carbonates (Jin et al., 2018; Zhang et al., 2018b).

China's general SOC distribution has been extensively studied. It has been noted that extremely low organic matter levels in desert grassland ecosystems may be a consequence of government-imposed grazing bans in large areas of western China, introduced in the $19^{\text {th }}$ century to restore land degraded by overgrazing (Wen et al., 2013). The C stock of Chinese grassland vegetation has been estimated at $1.0 \mathrm{Pg}$, and the total carbon stocks of Chinese grassland ecosystems at 29.1 Pg (Lu et al., 2018; Tang et al., 2018), with grasslands accounting for 21.55\% of $\mathrm{C}$ sequestration in Chinese terrestrial ecosystems. Grazing grassland ecosystems is beneficial for humans as well as for maintaining essential ecosystem processes such as nutrient cycling. Grazing is an important form of ecological disturbance and control factor in preserving equilibrium in natural grassland ecosystems (Piñeiro et al., 2009). However, overgrazing can cause severe degradation of desert steppes or other grassland types, and can further reduce SOC below its already naturally-reduced levels caused by low precipitation and other environmental factors (Deng et al., 2016; Wang et al., 2016). Similarly, a reduction of SOC content in alpine 
meadow soils is also correlated with a degree of degradation (Yuan et al., 2019b). Restoring degraded grassland can increase grassland ecosystem carbon stocks, particularly soil C stocks. Higher soil $\mathrm{C}$ enhances the respiration of grassland soils and accelerates the decomposition of soil organic matter (He et al., 2019; Zhou et al., 2019).

Developing indices to measure degradation and guide restoration project management is an extremely complex undertaking. In a study of natural wetland restoration in Florida's Everglades, Doren et al. (2009) drew inspiration from existing restoration projects in California and the Chesapeake Bay to choose 11 ecological indicators for monitoring, based on 12 selection criteria. In a study of rangeland restoration in Iceland, researchers examined the importance of stakeholder attitudes towards restoration and the function of government policies on the achieved outcomes (Petursdottir et al., 2013). Following widespread government-implemented overgrazing of rangeland in the late $20^{\text {th }}$ century aimed at increasing food supply, rangeland grazing in China has been banned since the early 2000s in many provinces to promote ecosystem recovery. However, many farmers have mixed feelings about the current grazing bans and do not always abide by them. In response, the government introduced both enforcement and educational initiatives to inform farmers about the advantages of fencing (Fan et al., 2013; Ping \& Wang 2018). In years since, a number of studies have investigated the recovery of various restoration plots after fences were installed (Li et al., 2014; Li et al., 2013; Zhang et al., 2018a).

Fencing allows for the recovery of both above- and below-ground rangeland ecosystem components, including vegetation diversity, resilience, and physical and chemical soil properties (Yuan \& Hou 2014; Yuan et al., 2019a). Fencing eliminates the feeding and trampling effects of livestock (unless incursions occur), and as a result vegetation and biomass typically recover quickly from rare incursions ( $\mathrm{Li}$ et al., 2019). Ecosystem litter flow then increases and enters the soil, increasing the amount of soil carbon. Additionally, the restoration of vegetation cover protects surface SOC, reducing soil erosion, increasing the interception of wind-blown dust and other fine particles in the atmosphere (Ping \& Wang 2018), and promoting SOC (and in some cases, SIC) retention (Jin et al., 2018; Wu et al., 2016). Some results indicate that SIC storage 
100

101

102

103

104

105

106

107

108

109

110

111

112

113

114

115

116

117

118

119

120

121

122

deceases in restored grasslands because of the decrease in soil $\mathrm{pH}$ and increase in soil water content. SIC plays an important role in carbon sequestration and vegetation restoration in the semi-arid Loess Plateau (Liu et al., 2014). Other studies found increased SIC among all studied land-use type changes (grassland to farmland, grassland to forest, farmland to grassland, farmland to forest, and sandland to forest), while the magnitude and direction of SIC changes varied greatly with different land-use types (An et al., 2019).

Rangeland provides degraded grasslands with significant carbon sequestration potential (An et al., 2019) that should be utilized as an ecosystem service. For example, if grassland's carbon sequestration rate was between $46.7-129.2 \mathrm{~g} \mathrm{~cm}^{-2} \mathrm{yr}^{-1}$ with an average of $84.2 \mathrm{~g} \mathrm{~cm}^{-2} \mathrm{yr}^{-1}$, the average net carbon stocks would increase by $130.4 \mathrm{~g} \mathrm{~m}^{-2} \mathrm{yr}^{-1}$ (Wang et al., 2010). Related research conducted in China's semiarid steppe grassland of Inner Mongolia found that the plantsoil carbon stocks of fenced grassland were 1.5 times greater than those of Grazed grassland (Hoffmann et al., 2016; Yang et al., 2017).

A number of recent studies have investigated SOC recovery following fencing and grazing exclusion, but none of these explored soil depths below $100 \mathrm{~cm}$. In order to further examine the recovery of overgrazed grassland, we studied the recovery time course of both SOC and SIC, as well as the interactions between the two deep soil carbon pools $(0-500 \mathrm{~cm})$. Since few studies on $\mathrm{C}$ cycling and post-fencing soil C recovery have included SIC or explored changes below 100 cm soil depth, our data will provide greater clarity on the impacts of land husbandry changes on $\mathrm{C}$ sequestration rates, both in China and abroad.

\section{Materials \& Methods}

\section{Study sites}

The studied site was located in the Yunwu Mountain National Nature Reserve $\left(36^{\circ} 10^{\prime}-36^{\circ} 17^{\prime} \mathrm{N}\right.$, $\left.106^{\circ} 21^{\prime}-106^{\circ} 27^{\prime} \mathrm{E}\right), 45 \mathrm{~km}$ northeast of Guyuan City, Ningxia Autonomous Region, China in the hinterland of the Loess Plateau at an altitude of 1700-2148 m. It belongs to the temperate semiarid climate zone. The mean annual precipitation for the period 1980-2014 was $425 \mathrm{~mm}$, with 60\%$75 \%$ of total precipitation occurring between July and September. The main soil types are locally 
127 known as 'mountain gray cinnamon' soil and 'black loess', which are Alfisols and Mollisols, 128 respectively, according to the USDA classification system. Atmospheric precipitation mainly 129 replenishes water resources. The region's dominant plants are Stipa bungeana, Stipa grandis, 130 Thymus mongolicus, Artemisias acrorum, and Potentilla acaulis.

131 Since 1980, the regional government has implemented several mountain closure and grazing 132 
154 The analyses for SOC, SIC, and $\mathrm{pH}$ were performed in triplicate on subsamples from the bulked 155 site samples. SOC and SIC were measured using an elemental analyzer (Vario EL/micro cube, 156 Germany) and soil $\mathrm{pH}$ value was measured using an acidity agent (PHS-3C pH acidometer, 157 China).

\section{Soil carbon calculations}

159 The SOC and SIC stocks ( $\left.\mathrm{Mg} \mathrm{hm}^{-2}\right)$ were calculated as follows (Li et al. 2019):

160

161

162

$$
\begin{aligned}
& \text { SOC storage }=\sum_{i=1}^{n} D_{i} \times B_{i} \times S O C_{i} \\
& \text { SIC storage }=\sum_{i=1}^{n} D_{i} \times B_{i} \times S I C_{i}
\end{aligned}
$$

Where $\mathrm{n}$ is the number of soil layers, $\mathrm{D}_{\mathrm{i}}$ is the soil depth $(\mathrm{cm}), \mathrm{B}_{\mathrm{i}}$ is the soil bulk density $\left(\mathrm{g} \mathrm{cm}^{-3}\right)$, $\mathrm{SOC}_{i}$ and $\mathrm{SIC}_{i}$ are the SOC content and SIC content (\%) of soil layer . $^{\circ}$

The soil total carbon (STC) stocks were calculated as:

$$
\text { STCstorage }=\text { SOCstorage }+ \text { SICstorage }
$$

And the changes in soil $\mathrm{C}$ stocks $\left(\mathrm{C}\right.$ change, $\left.\mathrm{Mg} \mathrm{hm}^{-2}\right)$ were:

$$
\text { Cchange }=C_{t}-C_{0}
$$

Where $C_{t}$ represents soil stocks in the fenced grassland $\left(\mathrm{Mg} \mathrm{hm}^{-2}\right)$, and $\mathrm{C}_{0}$ is the soil stocks in the grazed grassland $\left(\mathrm{Mg} \mathrm{hm}^{-2}\right)$.

Lastly, the rate of soil carbon stock change (RSS, $\mathrm{Mg} \mathrm{hm}^{-2} \mathrm{yr}^{-1}$ ) was estimated by the linear regression of change in soil $\mathrm{C}$ stocks with time since fencing:

$$
\text { Cchange }=f(\Delta \text { time })=y_{0}+K \times \Delta \text { time }
$$

Where $y_{0}$ is a constant, $K$ is the rate of soil $\mathrm{C}$ stock change $\left(\mathrm{Mg} \mathrm{hm}^{-2} \mathrm{yr}^{-1}\right)$, and $\Delta$ time is the fenced time interval (i.e., years from grazing cessation to the present).

\section{Statistical analyses}

Various statistical analyses were performed using the software packages SAS 9.4, Origin 2017, and Microsoft Excel. Since soil depth data taken from the same cores can suggest correlation across soil depths, all data were first analyzed using One-Way ANOVA comparing the time spent fenced off with soil depths as a statement of " mixed effect model" in Proc GLM in SAS 
180

181

182

183

184

185

186

187

188

189

190

191

192

193

194

195

196

197

198

199

200

201

202

203

204

205

206

(Li et al. 2019). For presentation and statistical purposes, the bulked samples from the nine sites (each consisting of 27 soil layers) were averaged across each of the six soil layers (0-40, 40-100, 100-200, 200-300, 300-400, and 400-500 cm soil depths). The soil depth effect had a degrees of freedom (df) of 5; the interaction effect between time fenced and soil depth had a df of 10 , with an error df of 30 and a total of $53(9 \times 6-1)$ df in each repeated measures ANOVA. SAS provides two options for adjusting the $p$-value of the main-factor $\mathrm{x}$ repeat-factor interaction across soil depths, and we used the adjusted $p$-value based on the Greenhouse-Geiser Epsilon. We then processed the SAS repeat measure output using the other packages. For example, we used SPSS to obtain the standard errors of individual means across soil depths, and Minitab Version 10.51 to perform Pearson correlation analyses.

\section{Results}

\section{Soil bulk density, soil moisture (SWC), and pH}

The observed soil bulk density values ranged from $0.91 \mathrm{~g} \mathrm{~cm}^{-3}$ in the $0-40 \mathrm{~cm}$ soil layer of the F15 plots to $1.67 \mathrm{~g} \mathrm{~cm}^{-3}$ in the $100-200 \mathrm{~cm}$ layer of the F30 plots. For subsoil with low SOC, typical values were $1.2-1.28 \mathrm{~g} \mathrm{~cm}^{-3}$. Values for the $0-40 \mathrm{~cm}$ layer were lower, reflecting the accumulation of SOC in the upper soil. For the grazed plots, the mean bulk density in the $0-40$ $\mathrm{cm}$ soil depth was $1.09 \mathrm{~g} \mathrm{~cm}^{-3}$, and was reduced to less than $1.00 \mathrm{~g} \mathrm{~cm}^{-3}$ in the F15 and F30 plots (Table 2). The results from repeated measures ANOVA showed that time fenced and soil depth both significantly affected soil bulk density $(\mathrm{F}=23.10, p<0.0001$; Table 3$)$. The high bulk density of $1.67 \mathrm{~g} \mathrm{~cm}^{-3}$ in the 100-200 cm layer of the F30 plots was atypical, since all the others were observed at less than $1.30 \mathrm{~g} \mathrm{~cm}^{-3}$, so we noted a correlation of $-0.802(\mathrm{p}=0.008)$ between soil bulk density and total carbon (TC) (Table 4). The pattern of variation in soil water content (SWC) generally followed the pattern of variation in SOC, with a correlation of $r=0.849$ (Table $4 ; p<0.001)$. Thus, SWC was higher in the surface horizon than in deeper horizons, and lower in grazed than in F15 and F30 grasslands (Table 2). Although SWC was (not unexpectedly) higher in the $100-300 \mathrm{~cm}$ soil horizon than in the $300-500 \mathrm{~cm}$ soil horizon $(9.4 \%$ and $10.3 \%$ on average, respectively; $p=0.399)$, SOC values were lower at the same depths $(0.47 \%$ and $0.29 \%$, 
207 respectively; $p=0.362$ ).

208 All soil $\mathrm{pH}$ values were alkaline, ranging from the lowest observed value of 7.76 in the $0-40 \mathrm{~cm}$ 209 soil layer of F30 plots to 9.20 and 9.18 in the 200-300 and 300-400 cm soil layer of grazed plots. 210 Notably, across soil depth and fencing duration data, $\mathrm{pH}$ values were strongly negatively 211 correlated with SOC and strongly positively correlated with SIC $(\mathrm{r}=-0.890, p<0.001$ and $\mathrm{r}=$ $2120.713, p=0.001$, respectively; Table 4). $\mathrm{pH}$ was consistently lower in F15 and F30 plots than G 213 plots in soil up to $400 \mathrm{~cm}$ deep.

\section{Soil organic and inorganic carbon}

215 In grazed grassland, SOC g. $\mathrm{kg}^{-1}$ ranged from $14.3 \mathrm{~g} \cdot \mathrm{kg}^{-1}$ in the $0-40 \mathrm{~cm}$ soil horizon to 3.1 g. $\mathrm{kg}^{-1}$ 216 in the 400-500 $\mathrm{cm}$ soil horizon $(p<0.05)$. In F30 grassland, the corresponding values were 22.9 217 g. $\mathrm{kg}^{-1}$ (a 60\% increase compared to $\mathrm{G}, p<0.05$ ) and $3.1 \mathrm{~g} \cdot \mathrm{kg}^{-1}$ (unchanged). For the soil depth of 218 200-300 cm, F15 had lower SOC levels than grazed grasslands but F30 had the highest, and for the 300-500 cm soil depth, the SOC levels of F15 were not significantly different than grazed grasslands but F30 had higher levels (Table 5). By contrast, SIC values changed much less with soil depth, but were higher in the deep soil layers compared to surface levels in grazed sites $(\mathrm{p}<0.05)$. The opposite was true for F30 and F15 grassland when compared to grazed grassland (grazed 0-40 cm soil depth, 17.1 g.kg-1 SIC; grazed 400-500 cm soil depth, 18.9 g.kg-1 SIC; F30 0-40 cm soil depth, 10.8 g. $\mathrm{kg}^{-1}$ SIC; F30 400-500 cm soil depth, 16.9 g. $\mathrm{kg}^{-1}$ SIC) (Table 6; $p=0.0046$ for the GG adjusted, time fenced $\mathrm{x}$ soil depth interaction). Repeated measures ANOVA showed that time fenced and soil depth both significantly affected SOC content $(\mathrm{F}=502.4, p$ $<0.0001$; Table 3).

The SOC and SIC data are presented as total carbon stocks $\left(\mathrm{Mg} \mathrm{hm}^{-2}\right)$ in Figure 1, and Figures 2 and 3 show the changes relative to grazed sites. These data illustrate that the SOC accumulation at this set of sites extended below $100 \mathrm{~cm}$ soil depth and continued 15 and 30 years after fencing, as evidenced by a F15-F30 separation and positive movement relative to grazed plots at the 0-200 cm soil depth (Figures 2a, 3a). The rate of change for years 0-30 was different from the rate of change for years $0-15$, particularly in the $0-200 \mathrm{~cm}$ soil depths where SOC 
234 accumulation occurs. In all three of the upper soil layers (0-40, 40-100, and 100-200 cm soil

235

236

237

238

239

240

241

242

243

244

245

246

247

248

249

250

251

252

253

254

255

256

257

258

259

260

depths), SOC accumulation at the 40-100 $\mathrm{cm}$ soil depth occurred faster in the first 15 years after fencing, and occurred mainly in years $15-30$ at the 100-200 cm soil depth. A reciprocal trend was seen in SIC data, but because of greater variability in this data, the trend could not be confirmed as statistically significant.

After comparing the SOC and SIC data, the effects of fencing on SIC stock were considered non-significant below $200 \mathrm{~cm}$ soil depths. However, in the $0-200 \mathrm{~cm}$ soil depth, the SIC stock decrease was larger than the SOC stock increase, to the extent that total soil C stocks (SOC stock + SIC stock; TC) across the 0-500 $\mathrm{cm}$ sampled soil profile were lower at fenced sites compared to grazed sites (Grazed $1345 \mathrm{Mg} \mathrm{hm}^{-2}$; F30 $1310 \mathrm{Mg} \mathrm{hm}^{-2} ; p=0.0479$ ).

\section{Total carbon stock percentages of the SOC and SIC pools}

The average SOC stock was $270 \mathrm{Mg} \mathrm{hm}^{-2}$ in grazed grassland, $304.7 \mathrm{Mg} \mathrm{hm}^{-2}$ in F15, and 461.6 $\mathrm{Mg} \mathrm{hm}^{-2}$ in F30 grasslands. SOC stock significantly increased at the F30 sites, compared to the F15 sites, while the SIC stock showed an opposite trend. SIC stocks decreased with time fenced, suggesting that STC did not significantly differ with years fenced (Figure 4).

SOC stocks for the $0-40 \mathrm{~cm}$ soil depth significantly increased at F30 but not F15 sites (Figure 5A), while at 40-100 cm and 100-200 cm soil depths, SOC was significantly greater $(p<0.05)$ in F15 than in grazed sites, and significantly greater $(p<0.05)$ again in F30 than in F15 sites (Figures 5B, C). In contrast, SIC stocks were lower in F15 and F30 sites compared to grazed sites at all soil depths, and the reduction was greater for F30 than F15 sites at deeper soil depths of 40-100 and 100-200 cm $(p<0.05$; Figures 5D, E, F). When observing the combined effect of SOC and SIC changes, the STC for the $0-40 \mathrm{~cm}$ soil depth was reduced at F15 sites compared to grazed sites but had recovered at F30 sites; at 40-100 cm soil depths, the STC was reduced at F15 and F30 sites compared to Grazed sites; and at 100-200 cm soil depths, the STC did not differ among F15, F30, and grazed sites (Figures 5G, H, I).

\section{Discussion}

China has some of the largest natural grasslands in the world. As previously mentioned, many of 
261 these grasslands were overgrazed in the latter part of the $20^{\text {th }}$ century, which has encouraged the 262 planning of regional grassland recovery programs. The soils of China's Loess Plateau, lying in 263 the middle reaches of the Yellow River, were formed from aeolian deposits accumulated over 264 millennia and are sometimes more than $100 \mathrm{~m}$ thick (Li et al., 2019; Liu et al., 2020). From a soil

265

266

267

268

269

270

271

272

273

274

275

276

277

278

279

280

281

282

283

284

285

286

287

formation perspective, this suggests the absence of a stage involving the weathering of parent material such as rock, with the parent material evident at a certain depth, and a soil matrix transition with depth reflecting the gradation from soil to parent material. This raises the question: to what depth will processes like soil $\mathrm{C}$ regeneration penetrate during the restoration of the homogeneous loess matrix? Previous studies have explored SOC changes over time under different land uses (Chen et al., 2017b), SOC decline under continued grazing (Yuan \& Hou 2014), and SOC increase after the Loess Plateau's steppe grassland was fenced off to protect from grazing (Liu et al., 2017; Zhang et al., 2015). That final study also showed that SOC increase during grassland restoration is accompanied by SIC decrease, and they concluded that both SOC and SIC should be measured when compiling soil C inventories for regional development planning (Zhang et al., 2015). Additionally, Chen et al. studied sites for 3 years and detected statistically significant changes in soil properties within that period (Chen et al., 2017b). We chose sites that formed a chronosequence to observe changes over a longer time period, which is a standard method used in China (Liu et al., 2017; Zhao et al., 2019).

SOC levels at the grazed sites were low and the $\mathrm{pH}$ was somewhat alkaline (SOC $14.3 \mathrm{~g} \mathrm{~kg}^{-1}$ and $7.2 \mathrm{~g} \mathrm{~kg}^{-1}$ for $0-40$ and 40-100 $\mathrm{cm}$ soil depths, respectively; with corresponding $\mathrm{pH}$ values 8.62 and 8.83), reflecting the cold, arid climate of the Loess Plateau and modest litter returns of a plant community with a net primary productivity of around $3-5 \mathrm{Mg} \mathrm{hm}^{-2}$ year-1 dry matter that is subject to grazing. However, our data confirm the beneficial changes in soil properties that follow grazing exclusion reported in other studies, with a $60 \%$ increase in SOC levels for the 0 $40 \mathrm{~cm}$ soil depth at the F30 sites, decreased soil BD, decreased alkalinity, and increased SWC. Our sampling also extended to $500 \mathrm{~cm}$ depths and we observed major SOC accumulation in the 100-200 cm soil horizon (Table 5; Figure 5), which was not detected by other studies only using 
288

289

290

291

292

293

294

295

296

297

298

299

300

301

302

303

304

305

306

307

308

309

310

311

312

313

314

a $100 \mathrm{~cm}$ sampling depth.

We also confirmed the negative correlation between SOC increase and SIC decrease over time (Liu et al., 2017) (Figure 4). When the means (Tables 2,5,6) for the six measured soil depths and years fenced (grazed, F15, or F30) were compiled into a correlation matrix (Table 4), the correlation coefficient for SOC and SIC was $-0.738(p<0.001)$. Considering the linked correlations between SOC and other soil properties (Table 4), particularly the SOC-pH correlation of -0.890 , we concluded that the SOC-SIC antagonism in these soils is a shift in the chemical balance shown in Equation 1.1 (Liu et al. 2017) away from carbonate formation through the SOC-induced reduction in alkalinity (i.e., $\mathrm{pH}$ decrease).

An important factor in restoring grassland degraded by historic overgrazing and in predicting the greenhouse gas implications of environmental management policies is the time frame for recovery. Our SOC data were extremely consistent across sites, making the SOC accumulation shown in years 0 to 15 of the site's chronosequence significantly different from years 15 to 30 .

Further research will be needed to determine if the $\mathrm{pH}$-mediated loss of SIC associated with SOC build up after fencing applies to the majority of soil types or if it is specific to soils with particular parent materials or properties. However, it is clear that predicting the greenhouse gas implications of land restoration programs is not as simple as measuring SOC as an indicator of cumulative $\mathrm{CO}_{2}$ sequestration. In this case, the SOC-SIC interactions of interest persisted to 200 cm soil depths, much deeper than is usually sampled in the majority of other studies. Our findings can be applied internationally for other geographic regions with similar climates.

In summary, our data confirms the SOC accumulation found after grassland restorative fencing reported by other studies, as well as the associated loss of SIC reported by Liu and Ping (Liu et al., 2017; Ping \& Wang 2018). We provide new insight into the SOC accumulation dynamics of the deep loessial soil in a semi-arid climate, and how they continue to evolve over 30 years and to a soil depth of $200 \mathrm{~cm}$.

\section{Conclusions}

This study compared the vertical distribution of SOC and SIC in a semi-arid loessial soil to a 
315

316

317

318

319

320

321

322

323

324

325

326

327

328

329

330

331

332

333

334

335

336

337

338

339

340

341

342

343

344

345

346

347

depth of $500 \mathrm{~cm}$ at replicated sites under historical continuous grazing $(\mathrm{G})$ or sites where grazing had been fenced off 15 (F15) or 30 (F30) years prior to the study. We confirmed prior findings on SOC accumulation after grazing exclusion, but few, if any, previous studies have sampled below $100 \mathrm{~cm}$ soil depths. Our deeper sampling provided new insights and revealed substantial SOC accumulation in the $100-200 \mathrm{~cm}$ soil depths 15 to 30 years after fencing. This finding indicates that slow diffusion processes intensify the soil property changes caused by increased litter return after fencing. As previously reported, the SOC accumulation over time is largely offset by SIC loss. The present study found correlations across the dataset between soil properties to clarify that the SOC-SIC antagonism is $\mathrm{pH}$-mediated. The new information from this study may be factored into soil C inventory calculations for loessial soils in similar climates internationally.

\section{Acknowledgement}

We thank the all staff members of Guyuan National Nature Reserve for providing field assistance for us to collect soil samples in the Yunwu mountain.

\section{References}

An H, Li QL, Yan X, Wu XZ, Liu RT, and Fang Y. 2019. Desertification control on soil inorganic and organic carbon accumulation in the topsoil of desert grassland in Ningxia, northwest China. Ecological Engineering 127:348-355. 10.1016/j.ecoleng.2018.12.014

An H, Wu XZ, Zhang YR, Tang Zhuang S. 2019. Effects of land-use change on soil inorganic carbon: A metaanalysis. Geoderma 353: 273-282. 10.1016/j.geoderma.2019.07.008

Bao ZH, Cai KD, Sun M, Xiao WJ, Wan B, Wang YN, Wang XS, and Xia XP. 2018. Continental crust melting induced by subduction initiation of the South Tianshan Ocean: Insight from the Latest Devonian granitic magmatism in the southern Yili Block, NW China. Journal of Asian Earth Sciences 153:100-117. 10.1016/j.jseaes.2017.04.026

Chen B, Yang R, Liu ZH, Sun HL, Yan H, Zeng QR, Zeng SB, Zeng C, and Zhao M. 2017a. Coupled control of land uses and aquatic biological processes on the diurnal hydrochemical variations in the five ponds at the Shawan Karst Test Site, China: Implications for the carbonate weathering-related carbon sink. Chemical Geology 456:58-71. 10.1016/j. chemgeo. 2017.03. 006

Chen X, Hou F, Matthew C, and He X. 2017b. Soil C, N, and P Stocks Evaluation Under Major Land Uses on China's Loess Plateau. Rangeland Ecology \& Management 70: 341-347. 10. 1016/j. rama. 2016.10.005

Deng L, Wang KB, Li JP, Zhao GW, and Shangguan Z. 2016. Effect of soil moisture and atmospheric humidity on both plant productivity and diversity of native grasslands across the Loess Plateau, China. Ecological 
Engineering 94:525-531. 10.1016/j.ecoleng.2016.06.048

Doren RF, Trexler JC, Gottlieb AD, and Harwell MC. 2009. Ecological indicators for system-wide assessment of the greater everglades ecosystem restoration program. Ecological Indicators 9:S2-S16.10.1016/j.ecolind. 2008.08.009

Dou X, Deng Q, Li M, Wang W, Zhang Q, and Cheng X. 2013. Reforestation of Pinus massoniana alters soil organic carbon and nitrogen dynamics in eroded soil in south China. Ecological Engineering 52:154-160. 10.1016/j.ecoleng.2012.12.099

Fan YJ, Hou XY, Shi HX, and Shi SL. 2013. Effects of grazing and fencing on carbon and nitrogen reserves in plants and soils of alpine meadow in the three headwater resource regions. Russian Journal of Ecology 44:80-88. 10.1134/S1067413612050165

He YL, Qi YC, Peng Q, Dong YS, Guo SF, Yan ZQ, and Li ZL. 2019. Carbon availability affects soil respiration response to drying-rewetting cycles in semiarid grasslands of China under nitrogen deposition. European Journal of Soil Biology 93. UNSP 10308910.1016/j.ejsobi.2019.103089

Hoffmann C, Giese M, Dickhoefer U, Wan HW, Bai YF, Steffens M, Liu CY, Butterbach-Bahl K, and Han XG. 2016. Effects of grazing and climate variability on grassland ecosystem functions in Inner Mongolia: Synthesis of a 6-year grazing experiment. Journal of Arid Environments 135:50-63. 10.1016/j.jaridenv. 2016. 08. 003

Jin SF, Tian XH, and Wang HS. 2018. Hierarchical responses of soil organic and inorganic carbon dynamics to soil acidification in a dryland agroecosystem, China. Journal of Arid Land 10: 726-736. 10. 1007/ s40333-0180066-2

Li JP, Ma HB, Xie YZ, Wang KB, and Qiu KY. 2019. Deep soil C and N pools in long-term fenced and overgrazed temperate grasslands in northwest China. Scientific Reports 9. ARTN 1608810.1038/s41598-019-52631-6.

Li Q, Zhou DW, Jin YH, Wang ML, Song YT, and Li GD. 2014. Effects of fencing on vegetation and soil restoration in a degraded alkaline grassland in northeast China. Journal of Arid Land 6:478-487. 10.1007/s40333-013-0207-6

Li YY, Dong SK, Wen L, Wang XX, and Wu Y. 2013. The effects of fencing on carbon stocks in the degraded alpine grasslands of the Qinghai-Tibetan Plateau. Journal of Environmental Management 128:393-399. 10.1016/j.jenvman.2013.05.058

Liu HF, Wang XK, Liang CT, Ai ZM, Wu Y, Xu HW, Xue S, and Liu GB. 2020. Glomalin-related soil protein affects soil aggregation and recovery of soil nutrient following natural revegetation on the Loess Plateau. Geoderma 357. ARTN 11392110.1016/j.geoderma.2019.113921

Liu WG, W J, Cheng JM, Li W J. 2014. Profile distribution of soil inorganic carbon along a chronosequence ofgrassland restoration on a 22-year scale in the Chinese Loess Plateau. Catena 121: 321-329. 10.1016/j.catena. 2014.05.019

Liu Y, Dang ZQ, Tian FP, Wang D, and Wu GL. 2017. Soil Organic Carbon and Inorganic Carbon Accumulation Along a 30-year Grassland Restoration Chronosequence in Semi-arid Regions (China). Land Degradation \& Development 28:189-198. 10.1002/ldr.2632

Lu F, Hu HF, Sun WJ, Zhu JJ, Liu GB, Zhou WM, Zhang QF, Shi PL, Liu XP, Wu X, Zhang L, Wei XH, Dai LM, Zhang KR, Sun YR, Xue S, Zhang WJ, Xiong DP, Deng L, Liu BJ, Zhou L, Zhang C, Zheng X, Cao JS, Huang Y, He NP, Zhou GY, Bai YF, Xie ZQ, Tang ZY, Wu BF, Fang JY, Liu GH, and Yu GR. 2018. Effects of national ecological restoration projects on carbon sequestration in China from 2001 to 2010. 
Proceedings of the National Academy of Sciences of the United States of America 115:4039-4044. 10.1073/pnas.1700294115

Petursdottir T, Arnalds O, Baker S, Montanarella L, and Aradóttir ÁL. 2013. A Social\&\#8211;Ecological System Approach to Analyze Stakeholders\&\#8217; Interactions within a Large-Scale Rangeland Restoration Program. Ecology and Society 18. 10.5751/es-05399-180229

Piñeiro G, Paruelo JM, Jobbágy EG, Jackson RB, and Oesterheld M. 2009. Grazing effects on belowground C and N stocks along a network of cattle exclosures in temperate and subtropical grasslands of South America. Global Biogeochemical Cycles 23:n/a-n/a. 10.1029/2007gb003168

Ping XY, and Wang TM. 2018. Effects of fencing and grazing on the temporal dynamic of soil organic carbon content in two temperate grasslands in Inner Mongolia, China. Biological Rhythm Research 49:539-550. $10.1080 / 09291016.2017 .1386873$

Srinivasarao CH, Venkateswarlu B, Lal R, Singh AK, Kundu S, Vittal KPR, Patel JJ, and Patel MM. 2014. LongTerm Manuring and Fertilizer Effects on Depletion of Soil Organic Carbon Stocks under Pearl MilletCluster Bean-Castor Rotation in Western India. Land Degradation \& Development 25:173-183. 10.1002/ldr.1158

Tang XL, Zhao X, Bai YF, Tang ZY, Wang WT, Zhao YC, Wan HW, Xie ZQ, Shi XZ, Wu BF, Wang GX, Yan JH, Ma KP, Du S, Li SG, Han SJ, Ma YX, Hu HF, He NP, Yang YH, Han WX, He HL, Yu GR, Fang JY, and Zhou GY. 2018. Carbon pools in China's terrestrial ecosystems: New estimates based on an intensive field survey. Proceedings of the National Academy of Sciences of the United States of America 115:4021-4026. 10.1073/pnas.1700291115

Wang K, Deng L, Ren Z, Li J, and Shangguan Z. 2016. Grazing exclusion significantly improves grassland ecosystem $\mathrm{C}$ and $\mathrm{N}$ pools in a desert steppe of Northwest China. Catena 137:441-448. 10.1016/j.catena.2015.10.018

Wang Y, Li Y, Ye X, Chu Y, and Wang X. 2010. Profile storage of organic/inorganic carbon in soil: from forest to desert. Sci Total Environ 408:1925-1931. 10.1016/j.scitotenv.2010.01.015

Wen H, Niu D, Fu H, and Kang JJEES. 2013. Experimental investigation on soil carbon, nitrogen, and their components under grazing and livestock exclusion in steppe and desert steppe grasslands, Northwestern China. 70:3131-3141. 10.1007/s12665-013-2376-1

Wu GL, Liu Y, Fang NF, Deng L, and Shi ZH. 2016. Soil physical properties response to grassland conversion from cropland on the semi-arid area. Ecohydrology 9:1471-1479. 10.1002/eco.1740

Yang ZP, Baoyin T, Minggagud H, Sun HP, and Li FY. 2017. Recovery succession drives the convergence, and grazing versus fencing drives the divergence of plant and soil N/P stoichiometry in a semiarid steppe of Inner Mongolia. Plant and Soil 420:303-314. 10.1007/s11104-017-3404-9

Yuan H, and Hou F. 2014. Grazing intensity and soil depth effects on soil properties in alpine meadow pastures of Qilian Mountain in northwest China. Acta Agriculturae Scandinavica, Section B - Soil \& Plant Science 65:222-232. 10.1080/09064710.2014.992940

Yuan XB, Niu DC, Wang Y, Boydston A, Guo D, Li XD, Wen HY, Qin Y, and Fu H. 2019a. Litter decomposition in fenced and Grazed grasslands: A test of the home-field advantage hypothesis. Geoderma 354. UNSP 11387610.1016/j.geoderma.2019.07.034

Yuan ZQ, Jiang XJ, Liu GJ, Jin HJ, Chen J, and Wu QB. 2019b. Responses of soil organic carbon and nutrient stocks to human-induced grassland degradation in a Tibetan alpine meadow. Catena 178:40-48. 
430

431

432

433

434

435

436

437

438

439

440

441

442

443

444

445

446

10.1016/j.catena.2019.03.001

Zhang CP, Li XD, Wen HY, Wan CG, and Fu H. 2015. Variation of Q(10) values in a fenced and a Grazed grassland on the loess plateau, northwestern China. Soil Science and Plant Nutrition 61:629-640. 10.1080/00380768.2015.1036307

Zhang L, Liu JZ, Wang DJ, Wang H, Wu YL, and Lu Z. 2018a. Fencing for conservation?The impacts of fencing on grasslands and the endangered Przewalski's gazelle on the Tibetan Plateau. Science China-Life Sciences 61:1593-1595. 10.1007/s11427-016-5096-4

Zhang L, Zhao W, Zhang R, Cao H, and Tan WF. 2018b. Profile distribution of soil organic and inorganic carbon following revegetation on the Loess Plateau, China. Environmental Science and Pollution Research 25:30301-30314. 10.1007/s11356-018-3020-0

Zhao W, Zhang R, Cao H, and Tan WF. 2019. Factor contribution to soil organic and inorganic carbon accumulation in the Loess Plateau: Structural equation modeling. Geoderma 352:116-125. 10.1016/j. geoderma. 2019.06.005

Zhou GY, Luo Q, Chen YJ, Hu JQ, He M, Gao J, Zhou LY, Liu HY, and Zhou XH. 2019. Interactive effects of grazing and global change factors on soil and ecosystem respiration in grassland ecosystems: A global synthesis. Journal of Applied Ecology 56:2007-2019. 10.1111/1365-2664.13443 


\section{Table $\mathbf{1}$ (on next page)}

Location of studied sites. The Yanzhou District Grassland Management Station, located in Guyuan City, identified sites that were grazed (G) or fenced for 15 (F15) or 30 (F30) years.

Note: The number of years ( $\pm 1-2$ years) that sites were fenced in was determined in 2014 . 
1 Table 1. Location of studied sites. The Yanzhou District Grassland Management Station, located in Guyuan City,

2 identified sites that were grazed (G) or fenced for 15 (F15) or 30 (F30) years.

\begin{tabular}{ccccccc}
\hline Fenced period & Longitude & Latitude & Altitude $(\mathrm{m})$ & Ground cover $(\%)$ & Slope $\left(^{\circ}\right)$ & Slope aspect \\
\hline \multirow{2}{*}{$\mathrm{G}$} & $106^{\circ} 24^{\prime} 13^{\prime \prime} \mathrm{E}$ & $36^{\circ} 10^{\prime} 04^{\prime \prime} \mathrm{N}$ & 1761 & 40 & $17-19$ & Semi-sunny slope \\
& $106^{\circ} 24^{\prime} 13^{\prime \prime} \mathrm{E}$ & $36^{\circ} 10^{\prime} 01^{\prime \prime} \mathrm{N}$ & 1795 & 30 & $0-1$ & Sunny slope \\
& $106^{\circ} 24^{\prime} 11^{\prime \prime} \mathrm{E}$ & $36^{\circ} 10^{\prime} 00^{\prime \prime} \mathrm{N}$ & 1788 & 38 & $16-18$ & Semi-sunny slope \\
\hline \multirow{2}{*}{$\mathrm{F} 15$} & $106^{\circ} 22^{\prime} 53^{\prime \prime} \mathrm{E}$ & $36^{\circ} 13^{\prime} 31^{\prime \prime} \mathrm{N}$ & 1910 & 85 & $6-8$ & Semi-sunny slope \\
& $106^{\circ} 23^{\prime} 10^{\prime \prime} \mathrm{E}$ & $36^{\circ} 13^{\prime} 32^{\prime \prime} \mathrm{N}$ & 1940 & 95 & $0-1$ & Sunny slope \\
& $106^{\circ} 23^{\prime} 14^{\prime \prime} \mathrm{E}$ & $36^{\circ} 13^{\prime} 27^{\prime \prime} \mathrm{N}$ & 1954 & 97 & $5-7$ & Semi-sunny slope \\
\hline & $106^{\circ} 22^{\prime} 53^{\prime \prime} \mathrm{E}$ & $36^{\circ} 15^{\prime} 07^{\prime \prime} \mathrm{N}$ & 2077 & 100 & $0-1$ & Sunny slope \\
& $106^{\circ} 23^{\prime} 10^{\prime \prime} \mathrm{E}$ & $36^{\circ} 15^{\prime} 03^{\prime \prime} \mathrm{N}$ & 2048 & 100 & $13-15$ & Semi-sunny slope \\
& $106^{\circ} 23^{\prime} 14^{\prime \prime} \mathrm{E}$ & $36^{\circ} 16^{\prime} 02^{\prime \prime} \mathrm{N}$ & 2112 & 100 & $8-10$ & Semi-sunny slope \\
\hline
\end{tabular}

3 Note: The number of years $( \pm 1-2$ years $)$ that sites were fenced in was determined in 2014 . 


\section{Table 2 (on next page)}

Soil bulk density (BD), soil water content (SWC), and soil pH for $0-500 \mathrm{~cm}$ soil depths in grazed grassland (G), restored grassland, and areas fenced off for 15 (F15) or 30 (F30) years.

Changes in BD, SWC and pH content with years fenced and soil depth $(n=3$ sites for each mean value). Note: Different lowercase letters indicate significant $(p<0.05)$ differences between fencing times; different uppercase letters indicate significant differences $(p<0.05)$ between soil depths. 
1 Table 2. Soil bulk density (BD), soil water content (SWC), and soil pH for $0-500 \mathrm{~cm}$ soil depths in grazed grassland (G), 2 restored grassland, and areas fenced off for 15 (F15) or 30 (F30) years. Changes in BD, SWC and pH content with years

3 fenced and soil depth ( $\mathrm{n}=3$ sites for each mean value).

\begin{tabular}{|c|c|c|c|c|c|c|c|c|}
\hline & & & \multicolumn{6}{|c|}{ Soil depth $(\mathrm{cm})$} \\
\hline & & & $0-40$ & $40-100$ & $100-200$ & $200-300$ & $300-400$ & $400-500$ \\
\hline \multirow{7}{*}{$\begin{array}{c}\mathrm{BD} \\
\left(\mathrm{g} \mathrm{cm}^{-3}\right)\end{array}$} & G & Mean & $1.09 \mathrm{aC}$ & $1.12 \mathrm{aC}$ & $1.21 \mathrm{aB}$ & $1.23 \mathrm{aB}$ & $1.26 \mathrm{aAB}$ & $1.28 \mathrm{aA}$ \\
\hline & & SEM & 0.04 & 0.04 & $0.02 \mathrm{aB}$ & 0.02 & 0.01 & 0.01 \\
\hline & F15 & Mean & $0.91 \mathrm{bD}$ & $1.07 \mathrm{bC}$ & $1.23 \mathrm{bA}$ & $1.22 \mathrm{aB}$ & $1.23 \mathrm{bA}$ & $1.28 \mathrm{aA}$ \\
\hline & & SEM & 0.01 & 0.01 & 0.01 & 0.01 & 0.01 & 0.01 \\
\hline & F30 & Mean & $0.95 \mathrm{bE}$ & $0.99 \mathrm{cD}$ & $1.67 \mathrm{bA}$ & $1.23 \mathrm{aC}$ & $1.24 \mathrm{bB}$ & $1.26 \mathrm{bB}$ \\
\hline & & SEM & 0.01 & 0.01 & 0.01 & 0.02 & 0.01 & 0.01 \\
\hline & G & Mean & $12.34 \mathrm{bA}$ & $10.53 \mathrm{cAB}$ & $7.25 \mathrm{bC}$ & $8.14 \mathrm{bBC}$ & $9.67 \mathrm{aBC}$ & $10.03 \mathrm{aB}$ \\
\hline \multirow{4}{*}{$\begin{array}{c}\text { SWC } \\
(\%)\end{array}$} & & SEM & 0.01 & 0.01 & 0.01 & 0.01 & 0.01 & 0.01 \\
\hline & F15 & Mean & $14.91 \mathrm{aA}$ & $14.94 \mathrm{aA}$ & $8.73 \mathrm{bB}$ & $9.37 \mathrm{bBC}$ & $10.67 \mathrm{aB}$ & $11.81 \mathrm{aB}$ \\
\hline & & SEM & 0.01 & 0.01 & 0.01 & 0.01 & 0.01 & 0.01 \\
\hline & F 30 & Mean & $14.79 \mathrm{aA}$ & $13.99 \mathrm{bA}$ & $11.62 \mathrm{aC}$ & $10.99 \mathrm{aBC}$ & $10 \mathrm{aC}$ & $9.85 \mathrm{aC}$ \\
\hline \multirow{7}{*}{$\mathrm{pH}$} & & SEM & 0.01 & 0.01 & 0.01 & 0.01 & 0.01 & 0.01 \\
\hline & G & Mean & $8.62 \mathrm{aB}$ & $8.83 \mathrm{aB}$ & $8.92 \mathrm{aA}$ & $9.2 \mathrm{aA}$ & $9.18 \mathrm{aA}$ & $8.97 \mathrm{aA}$ \\
\hline & & SEM & 0.05 & 0.09 & 0.11 & 0.01 & 0.05 & 0.33 \\
\hline & F 15 & Mean & $8.04 \mathrm{aB}$ & $8.71 \mathrm{aA}$ & $8.84 \mathrm{aA}$ & $8.85 \mathrm{bA}$ & $8.85 \mathrm{bA}$ & $8.59 \mathrm{aA}$ \\
\hline & & SEM & 0.65 & 0.14 & 0.08 & 0.11 & 0.13 & 0.22 \\
\hline & F30 & Mean & 7.76bB & $8.33 \mathrm{bA}$ & $8.63 \mathrm{bA}$ & $8.89 \mathrm{bA}$ & $8.88 \mathrm{bA}$ & $9.04 \mathrm{aA}$ \\
\hline & & SEM & 0.18 & 0.07 & 0.1 & 0.1 & 0.1 & 0.04 \\
\hline
\end{tabular}

4 Note: Different lowercase letters indicate significant $(p<0.05)$ differences between fencing times; different uppercase letters

5 indicate significant differences $(p<0.05)$ between soil depths. 


\section{Table 3 (on next page)}

$\mathrm{F}$ and $p$-values from SAS repeated measures ANOVA in Proc GLM.

The effect time fenced (T), soil depth (D), the interaction between $T$ and $D(T * D)$ on soil bulk density (BD), soil gravimetric water content (SWC), soil pH, soil organic carbon (SOC) content, soil inorganic carbon (SIC) content, and soil total carbon (STC) content. $F_{2,6}, F_{5,30}$, and $\mathrm{F}_{10,30}$ indicate numerator and denominator degrees of freedom, respectively, of the $\mathrm{F}$ statistics for each ANOVA effect. For $D$ and $T * D, p$-values are based on the Greenhouse-Geisser epsilon option in SAS. 
1 Table 3. F and $p$-values from SAS repeated measures ANOVA in Proc GLM. The effect time fenced (T), soil depth (D),

2 the interaction between $\mathrm{T}$ and $\mathrm{D}\left(\mathrm{T}^{*} \mathrm{D}\right)$ on soil bulk density $(\mathrm{BD})$, soil gravimetric water content (SWC), soil pH, soil organic

3 carbon (SOC) content, soil inorganic carbon (SIC) content, and soil total carbon (STC) content. $\mathrm{F}_{2,6}, \mathrm{~F}_{5,30}$, and $\mathrm{F}_{10,30}$ indicate 4 numerator and denominator degrees of freedom, respectively, of the F statistics for each ANOVA effect. For D and T*D, $p$ 5 values are based on the Greenhouse-Geisser epsilon option in SAS.

\begin{tabular}{|c|c|c|c|c|c|c|}
\hline & \multicolumn{2}{|c|}{$\mathrm{T}$} & \multicolumn{2}{|c|}{$\mathrm{D}$} & \multicolumn{2}{|c|}{$\mathrm{T}^{*} \mathrm{D}$} \\
\hline & $\mathrm{F}_{2,6}$ & $p$ & $\mathrm{~F}_{5,30}$ & $p$ & $F_{10,30}$ & $p$ \\
\hline $\mathrm{BD}\left(\mathrm{g} \mathrm{cm}^{-3}\right)$ & 15.60 & 0.004 & 515.5 & $<0.0001$ & 23.10 & $<0.0001$ \\
\hline SWC (\%) & 10.47 & 0.011 & 50.21 & $<0.0001$ & 5.09 & 0.0002 \\
\hline $\mathrm{pH}$ & 5.18 & 0.049 & 15.96 & 0.0002 & 1.00 & 0.4465 \\
\hline $\operatorname{SOC}(\%)$ & 4390 & $<0.0001$ & 10324 & $<0.0001$ & 502.4 & $<0.0001$ \\
\hline SIC (\%) & 18.16 & 0.0028 & 9.14 & 0.0081 & 8.43 & 0.0046 \\
\hline STC (\%) & 1.94 & 0.224 & 94.56 & $<0.0001$ & 2.04 & 0.1750 \\
\hline
\end{tabular}

6 


\section{Table 4(on next page)}

Correlations between soil properties representing the effects of years fenced and soil depths.

Note: * represent significant correlation at the lever of $\mathrm{P}<0.05$. ** represent significant correlation at the lever of $\mathrm{P}<0.01$. 
1 Table 4. Correlations between soil properties representing the effects of years fenced and soil depths.

\begin{tabular}{crrrrr}
\hline & \multicolumn{1}{c}{ SOC } & \multicolumn{1}{c}{ SIC } & \multicolumn{1}{c}{ TC } & BD & SWC \\
\hline SIC & $-0.738^{*}$ & & & & \\
TC & $0.879^{* *}$ & -0.325 & & & \\
BD & $-0.883^{* *}$ & $0.613^{*}$ & $-0.802^{* *}$ & & \\
SWC & $0.849^{* *}$ & $-0.637^{*}$ & $0.739^{* *}$ & $-0.775^{* *}$ & \\
pH & $-0.890^{* *}$ & $0.713^{*}$ & $-0.742^{* *}$ & $0.816^{* *}$ & $-0.812^{* *}$ \\
\hline
\end{tabular}

2 Note: * represent significant correlation at the lever of $\mathrm{P}<0.05$.

$3 * *$ represent significant correlation at the lever of $\mathrm{P}<0.01$.

4

5 


\section{Table 5 (on next page)}

Soil organic carbon (SOC, $\mathrm{g} \mathrm{kg}^{-1}$ ) for 0-500 $\mathrm{cm}$ soil depths in grazed grassland (G) and in grassland under restoration, fenced for 15 (F15) or 30 (F30) years.

Changes in SOC content with years fenced and soil depth ( $n=3$ sites for each mean value). Note: Different lowercase letters indicate significant $(p<0.05)$ differences between fencing times; different uppercase letters indicate significant differences $(p<0.05)$ between soil depths. 
1 Table 5. Soil organic carbon (SOC, $\mathrm{g} \mathrm{kg}^{-1}$ ) for $0-500 \mathrm{~cm}$ soil depths in grazed grassland (G) and in grassland under

2 restoration, fenced for $15($ F15) or 30 (F30) years. Changes in SOC content with years fenced and soil depth ( $\mathrm{n}=3$ sites for each 3 mean value).

\begin{tabular}{lcllllll}
\hline & & \multicolumn{7}{c}{ Soil depth $(\mathrm{cm})$} \\
\cline { 3 - 8 } & SOC (g kg-1) & $0-40$ & $40-100$ & $100-200$ & $200-300$ & $300-400$ & $400-500$ \\
\hline G & Mean & $14.3 \mathrm{cA}$ & $7.2 \mathrm{cB}$ & $2.6 \mathrm{cD}$ & $3 \mathrm{bC}$ & $2.7 \mathrm{bD}$ & $3.1 \mathrm{bC}$ \\
& SEM & 0.26 & 0.07 & 0.08 & 0.05 & 0.04 & 0.11 \\
\multirow{2}{*}{ F15 } & Mean & $17.7 \mathrm{bA}$ & $12.4 \mathrm{bB}$ & $4.6 \mathrm{bC}$ & $2.7 \mathrm{cE}$ & $2.6 \mathrm{bE}$ & $2.9 \mathrm{cD}$ \\
& SEM & 0.02 & 0.13 & 0.01 & 0.08 & 0.07 & 0.02 \\
\multirow{2}{*}{ F 30 } & Mean & $22.9 \mathrm{aA}$ & $16.2 \mathrm{aB}$ & $11.7 \mathrm{aC}$ & $3.7 \mathrm{aE}$ & $3.2 \mathrm{aE}$ & $3.1 \mathrm{aD}$ \\
& SEM & 0.04 & 0.01 & 0.04 & 0.26 & 0.09 & 0.03 \\
\hline
\end{tabular}

4 Note: Different lowercase letters indicate significant $(p<0.05)$ differences between fencing times; different uppercase letters 5 indicate significant differences $(p<0.05)$ between soil depths. 


\section{Table 6(on next page)}

Soil inorganic carbon (SIC, $\mathrm{g} \mathrm{kg}^{-1}$ ) from 0-500 $\mathrm{cm}$ soil depths in grazed grassland (G) and in grassland under restoration, fenced for 15 (F15) or 30 (F30) years.

Changes in SIC content with years fenced and soil depth ( $n=3$ sites for each mean value). Note: Different lowercase letters indicate significant $(p<0.05)$ differences between fencing times; different uppercase letters indicate significant differences $(p<0.05)$ between soil depths. 
1 Table 6. Soil inorganic carbon (SIC, $\mathrm{g} \mathrm{kg}^{-1}$ ) from $0-500 \mathrm{~cm}$ soil depths in grazed grassland (G) and in grassland under

2 restoration, fenced for $15(\mathbf{F 1 5})$ or 30 (F30) years. Changes in SIC content with years fenced and soil depth ( $\mathrm{n}=3$ sites for each 3 mean value).

\begin{tabular}{llllllll}
\hline & & \multicolumn{7}{c}{ Soil depth $(\mathrm{cm})$} \\
\cline { 3 - 8 } & SIC $\left(\mathrm{g} \mathrm{kg}^{-1}\right)$ & $0-40$ & $40-100$ & $100-200$ & $200-300$ & $300-400$ & $400-500$ \\
\hline G & Mean & $17.1 \mathrm{aB}$ & $20.5 \mathrm{aA}$ & $15.3 \mathrm{aA}$ & $15.4 \mathrm{aA}$ & $17.3 \mathrm{aA}$ & $18.9 \mathrm{aA}$ \\
& SEM & 0.08 & 0.01 & 0.06 & 0.04 & 0.21 & 0.01 \\
\multirow{2}{*}{ F15 } & Mean & $9.1 \mathrm{bB}$ & $12.9 \mathrm{bB}$ & $16.1 \mathrm{aA}$ & $16.4 \mathrm{aA}$ & $16.7 \mathrm{aA}$ & $16.2 \mathrm{aA}$ \\
& SEM & 0.02 & 0.03 & 0.11 & 0.01 & 0.06 & 0.02 \\
\multirow{2}{*}{ F30 } & Mean & $10.8 \mathrm{bB}$ & $9.6 \mathrm{bB}$ & $10.2 \mathrm{bB}$ & $17.9 \mathrm{aA}$ & $16.6 \mathrm{aA}$ & $16.2 \mathrm{aA}$ \\
& SEM & 0.03 & 0.07 & 0.05 & 0.14 & 0.18 & 0.03 \\
\hline
\end{tabular}

4 Note: Different lowercase letters indicate significant $(p<0.05)$ differences between fencing times; different uppercase letters 5 indicate significant differences $(p<0.05)$ between soil depths.

6 
Figure 1

The vertical distribution of soil carbon stocks for grazed grasslands (G), and for restoring grasslands that had been fenced for 15 (F15) or 30 (F30) years, respectively.

A) soil organic carbon (SOC), and B) soil inorganic carbon (SIC) stocks ( $\mathrm{Mg} \mathrm{hm}^{-2}$ ). Different lowercase letters indicate significant $(p<0.05)$ differences between $G, F 15$, and F30 sites.
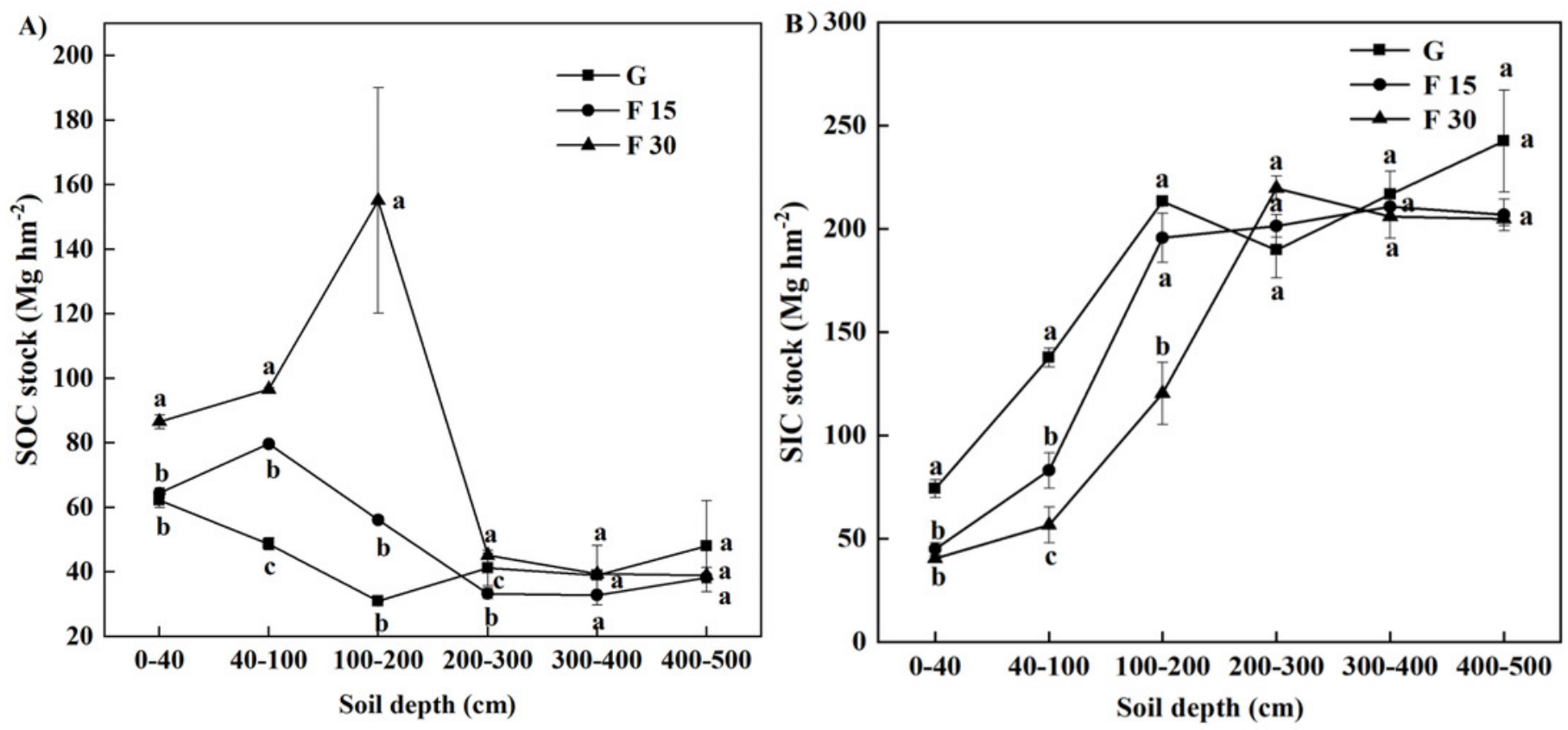
Figure 2

Carbon stock change differences between grazed Loess Plateau grassland and grassland fenced for 15 (F15) or 30 (F30) years, respectively, for vertical distribution.

(A) soil organic carbon, (B) soil inorganic carbon. Different lowercase letters indicate significant $(p<0.05)$ differences among the different soil depths.
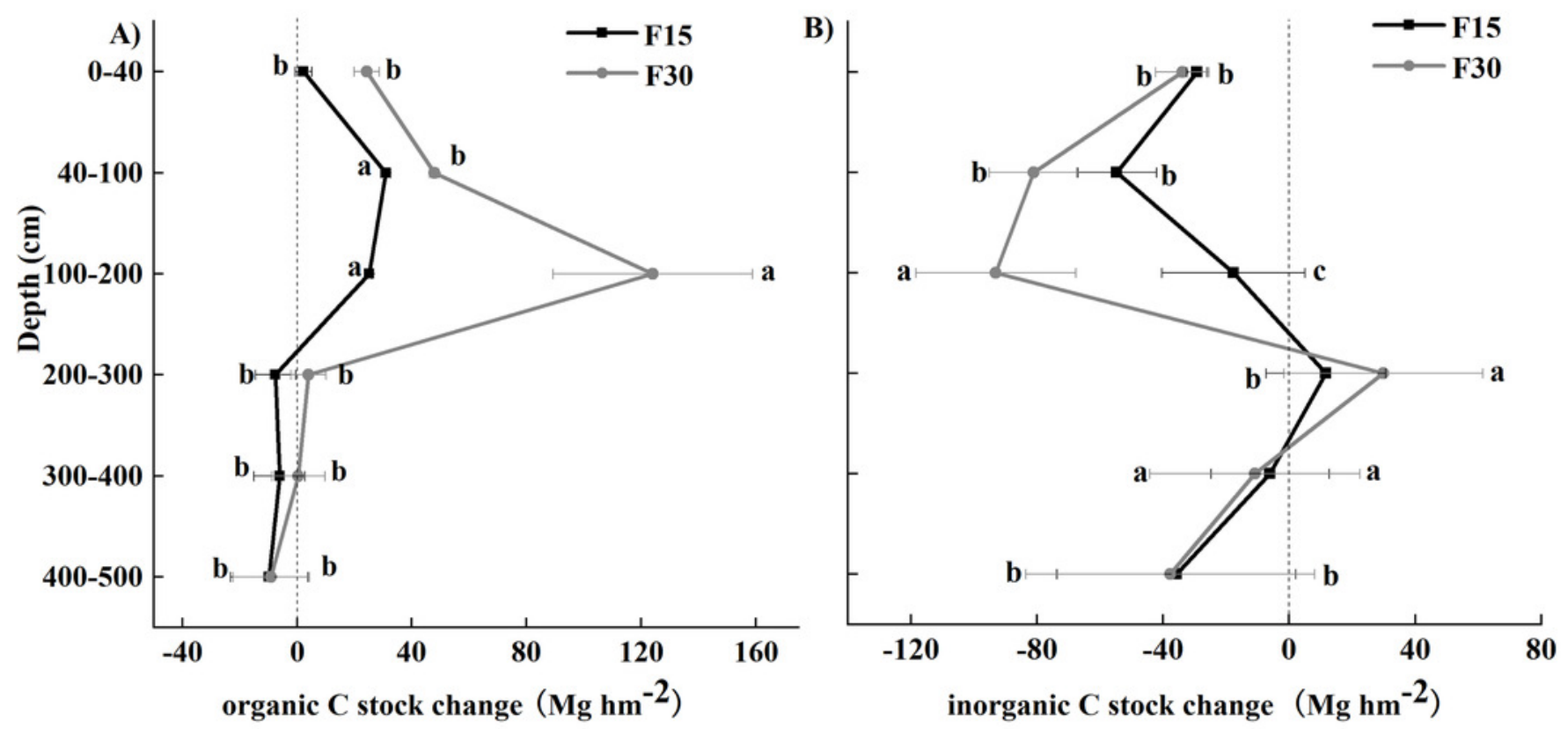
Figure 3

Rates of carbon change relative to grazed grassland and grasslands fenced for 15 (F15) or 30 (F30) years, respectively.

(A) Rate of soil organic carbon stock change and (B) Rate of soil inorganic carbon stock change. Error bars represent standard errors of means. Different lowercase letters indicate significant $(p<0.05)$ differences among the different soil depths.
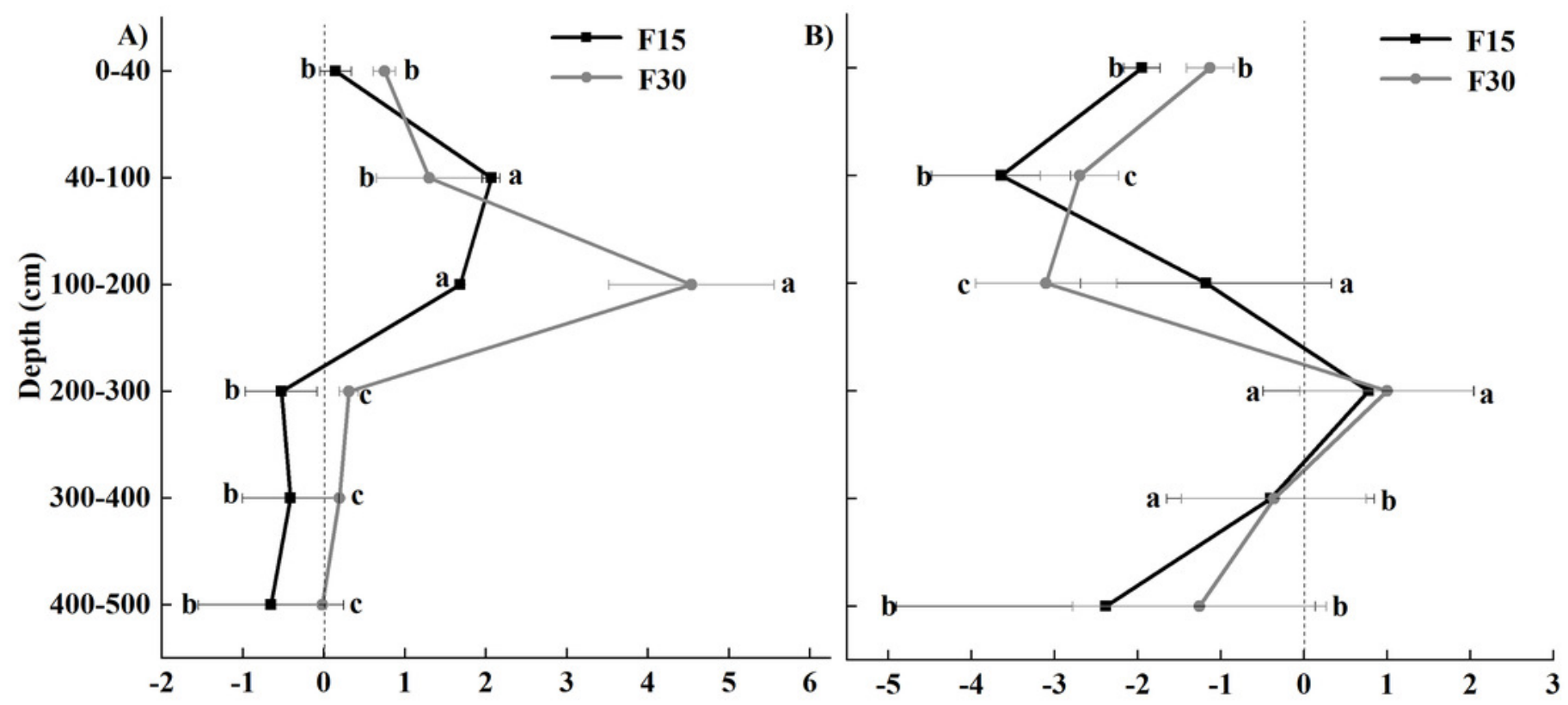

Rate of Organic C stock change $\left(\mathrm{Mg} \mathrm{hm}^{-2} \mathrm{yr}^{-1}\right)$

Rate of Inorganic carbon stock change $\left(\mathrm{Mg} \mathrm{hm}^{-2} \mathrm{yr}^{-1}\right)$ 


\section{Figure 4}

Soil organic carbon (SOC) and inorganic carbon (SIC) stocks over the total $0-500 \mathrm{~cm}$ soil profile for grazed grassland (G) and grassland fenced for 15 (F15) or 30 (F30) years, respectively.

Different lowercase letters indicate significant $(p<0.05)$ differences in SOC with time fenced.

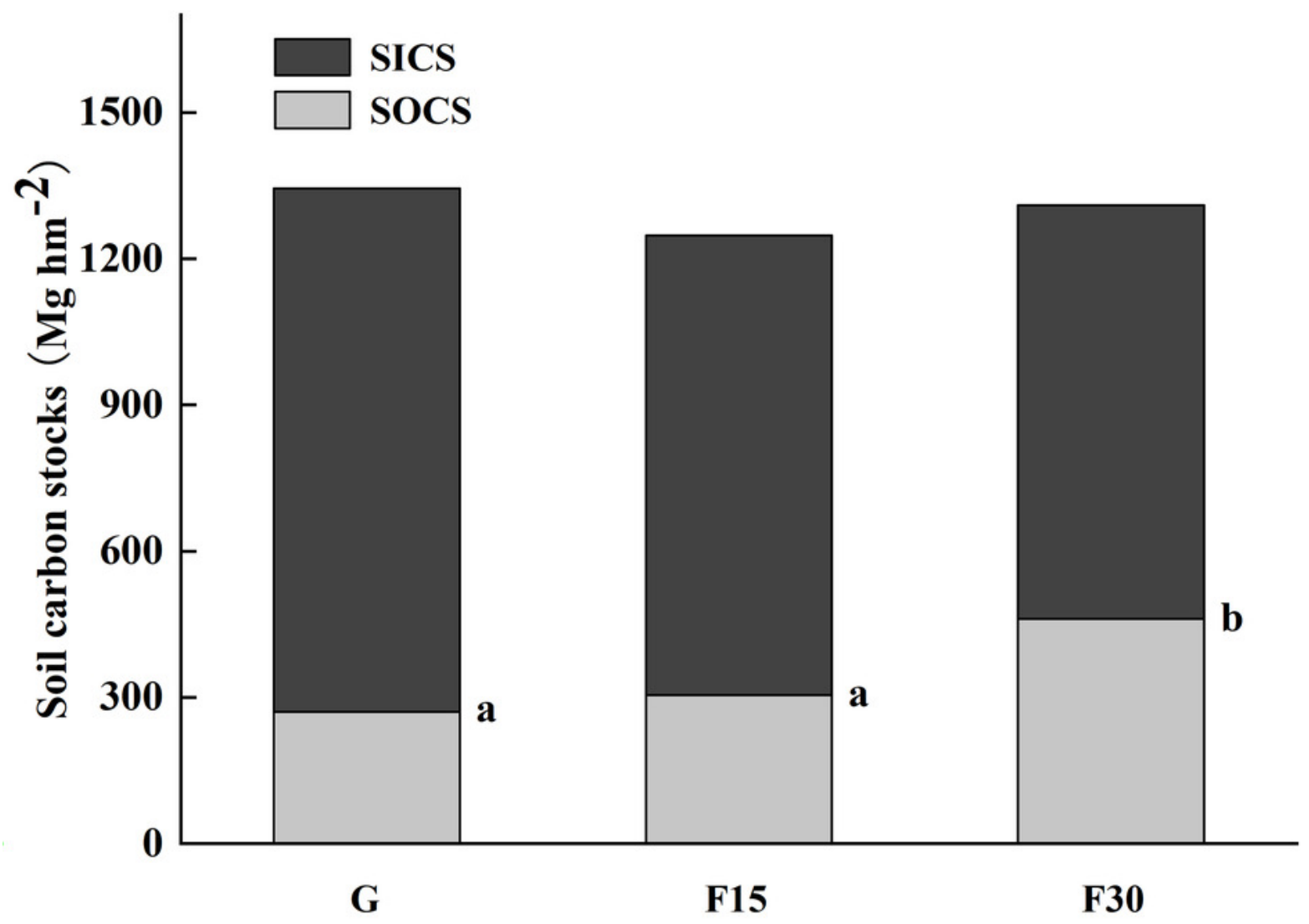




\section{Figure 5}

Changes in three soil depth bands $(0-40,40-100,100-200 \mathrm{~cm})$ for soil organic carbon (SOC) (A, B, C) $\square$ soil inorganic carbon (SIC) (D, E, F), and soil total carbon (STC) stock (G, $H, I)$.

In the X-axes, G, F15, and F30 denote grazed grassland and grassland fenced for 15 or 30 years, respectively. Note: Uppercase letters with each error bar indicate significant $(p<0.05)$ changes with length of time fenced. 

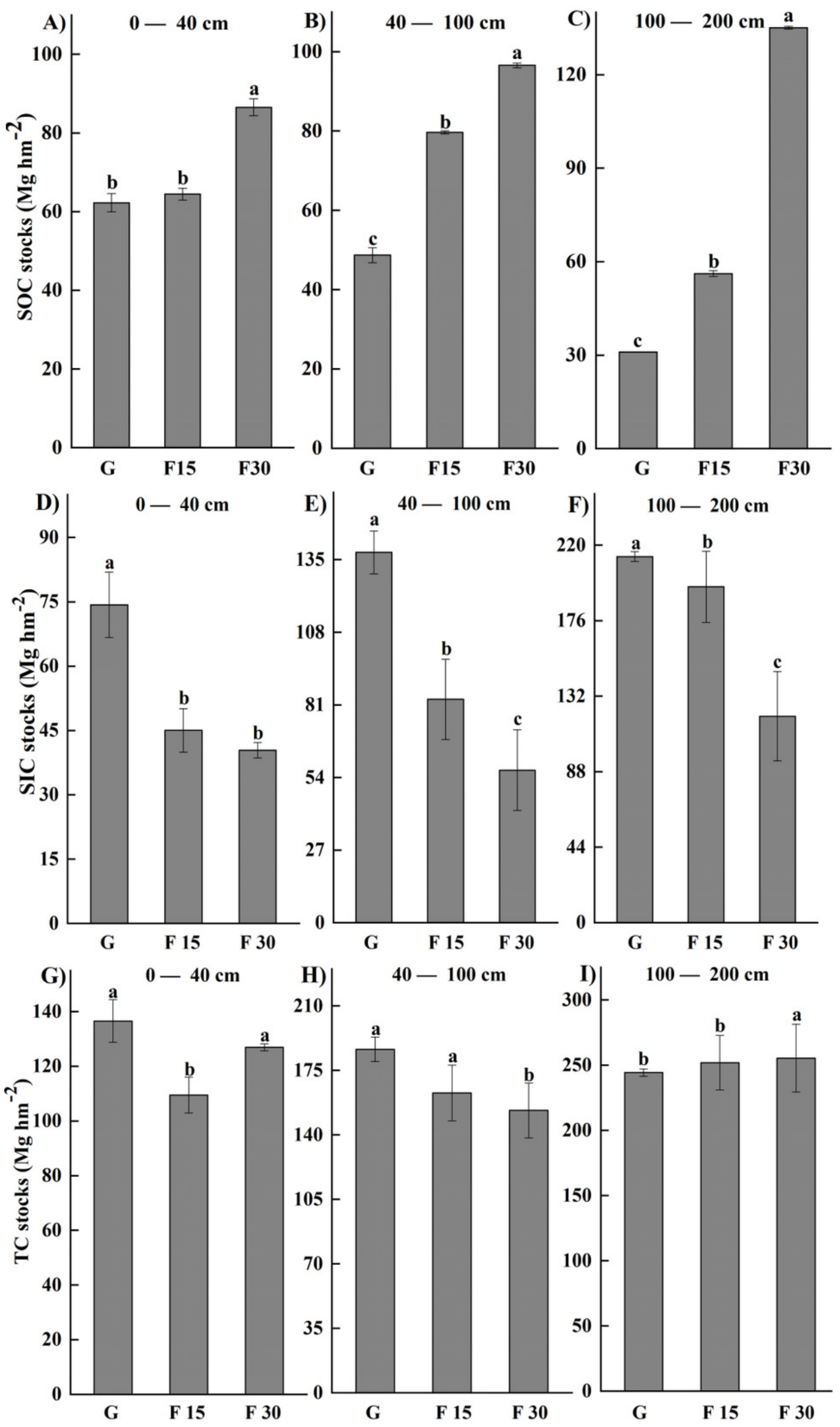